\section{Digital preservation}

The PARS Working Group on Defining Digital Preservation of the Association for Library Collections and Technical Services (ALCTS) has released a new de nition of digital preservation, expressed in three levels of complexity. The short de nition is one sentence, the medium de nition is one paragraph, and the long de nition is three paragraphs with lists of the activities necessary to ensure content description, integrity, and maintenance. This de nition was accepted as an information document by the ALA Council in January 2008.

For more information and text of the definitions, go to www.ala.org/ala/alcts /newslinks/digipres/index.cfm.

\section{Emergency responders}

The Lessons Applied initiative of the Heritage Emergency National Task Force has produced a new poster/booklet, Working with Emergency Responders: Tips for Cultural Institutions. This publication explains who emergency responders are, what members of the cultural community should say to them, how to build relationships, and what they need to know. Many of the recommended actions should be implemented before an emergency occurs, but others are applicable during and after an emergency.

Posters are available for $\$ 2$ each from Heritage Preservation at www.heritagepreservation. org/catalog/product.asp?intProdID $=39$. The booklet is available as a free PDF at the same URL.

\section{FACET}

The Sound Directions project at Indiana University and Harvard University has released the Field Audio Collection Evaluation Tool (FACET). It is an open source software tool

Jane Hedberg is preservation program officer at Harvard University Library, e-mail: jane_hedberg@harvard.edu; fax: (617) 496-8344 that ranks the risk of deterioration or format failure for audio collections created in the eld, and assists collection managers in setting preservation priorities. It covers open reel tape (polyester, acetate, paper, and PVC bases), analog audio cassettes, digital audio tape, lacquer discs, aluminum discs, and wire recordings. FACET consists of software, a procedures manual, a 92-page document that describes the audio formats, and sample worksheets.

FACET is available free-of-charge at www. dlib.indiana.edu/projects/sounddirections /facet/index.shtml.

\section{Storage workshop}

The Conservation Center for Art and Historic Artifacts (CCAHA) is presenting a two-day program, A Space Odyssey: Storage Strategies for Cultural Collections, September 23 24, 2008, in Philadelphia. This workshop will cover the basics of storage, allocating resources, funding, space planning, open and off-site storage, moving collections, storage furniture, optimal environments, environmental monitoring, HVAC systems, cold storage, and regulating environments in historic structures. Speakers include Georgina Bath from the Smithsonian American Art Museum, Walt Crimm from EwingCole Architects, Cathy Fields and Julie Frey from the Litch eld Historical Society, Kristen Froehlich from the Atwater Kent Museum of Philadelphia, Michael Henry from Watson \& Henry Associates, Emily Kaplan from the Smithsonian National Museum of the American Indian, Jim Reilly from the Image Permanence Institute, and Barbara Lemmen, Lee Price, and Glen Ruzicka from CCAHA.

Registration costs $\$ 225$ for CCAHA members and $\$ 250$ for nonmembers. For more information, contact Kim Andrews, CCAHA, 264 S. 23rd St., Philadelphia, PA 19103; phone: (215) 545-0613; fax: (215) 735-9313; e-mail: kandrews@ccaha.org; URL: www. ccaha.org. $n$ 